\title{
Electronic Properties of Mono-Substituted Tetraferrocenyl Porphyrins in Solution and on a Gold Surface: Assessment of the Influencing Factors for Photoelectrochemical Applications
}

\author{
Andrea Vecchi, ${ }^{[\mathrm{a}]}$ Nathan R. Erickson, ${ }^{[\mathrm{b}]}$ Jared R. Sabin, ${ }^{[\mathrm{b}]}$ Barbara Floris, ${ }^{[\mathrm{a}]}$ Valeria Conte, ${ }^{[\mathrm{a}]}$ \\ Mariano Venanzi, ${ }^{[a]}$ Pierluca Galloni, ${ }^{*[a]}$ and Victor N. Nemykin ${ }^{*[b]}$
}

\begin{abstract}
Two unsymmetric meso-tetraferrocenyl-containing porphyrins of general formula $\mathrm{Fc}_{3}(\mathrm{FcCOR})$ Por ( $\mathrm{Fc}=$ ferrocenyl, $\mathrm{R}=\mathrm{CH}_{3}$ or $\left(\mathrm{CH}_{2}\right)_{5} \mathrm{Br}$, Por = porphyrin) were prepared and characterized by a variety of spectroscopic methods, whereas their redox properties were investigated using cyclic voltammetry (CV) and differential pulse voltammetry (DPV) approaches. The mixed-valence $\left[\mathrm{Fc}_{3}(\mathrm{FcCOR}) \mathrm{Por}\right]^{n+}(n=1,3)$ were investigated using spectroelectrochemical as well as chemical oxidation methods and corroborated with density functional theory (DFT) calculations. Inter-valence charge-
\end{abstract}

transfer (IVCT) transitions in $\left[\mathrm{Fc}_{3}(\mathrm{FcCOR}) \mathrm{Por}\right]^{+}$were analyzed, and the resulting data matched closely previously reported complexes and were assigned as Robin-Day class II mixedvalence compounds. Self-assembled monolayers (SAMs) of a thioacetyl derivative $\left(\mathrm{FC}_{3}\left(\mathrm{FcCO}\left(\mathrm{CH}_{2}\right)_{5} \mathrm{SCOCH}_{3}\right)\right.$ Por) were also prepared and characterized. Photoelectrochemical properties of SAMs in different electrolyte systems were investigated by electrochemical techniques and photocurrent generation experiments, showing that the choice of electrolyte is critical for efficiency of redox-active SAMs.

\section{Introduction}

Because of well-established electron-donor properties, ferrocene-containing donor-acceptor dyads, with strong absorption of the solar spectrum and tunable electron-transfer and redox properties, have been intensively studied over the last decades as prominent light-harvesting blocks for organic photovoltaics (OPVs) and dye-sensitized solar cells (DSSCs). ${ }^{[1]}$ Furthermore, such systems were suggested as potentially useful components for redox-driven fluorescence, molecular electronics, ionrecognition, and optical limiting devices. ${ }^{[2]}$ Tetraazaporphyrins ${ }^{[3]}$ phthalocyanines, ${ }^{[4]}$ corroles, $^{[5]}$ porphyrins, ${ }^{[6-10]}$ and (aza)BODIPY $^{[11]}$ substituted with one or several ferrocenyl groups are of great interest because of their rich redox chemistry and redox-switchable spectroscopic versatility. Potential use of ferrocene-containing porphyrins and other organic compounds in DSSCs, OPVs, molecular electronics, and photocatalysis require their surface immobilization, ${ }^{[12]}$ and in particularly simple synthetic routes, for formation of well-defined self-assembled

[a] Dr. A. Vecchi, Prof. B. Floris, Prof. V. Conte, Prof. M. Venanzi, Dr. P. Galloni Dipartimento di Scienze e Tecnologie Chimiche

Università di Roma "Tor Vergata"

Via della Ricerca Scientifica, 00133 Rome (Italy)

E-mail:galloni@scienze.uniroma2.it

[b] N. R. Erickson, J. R. Sabin, Prof. V. N. Nemykin

Department of Chemistry \& Biochemistry

University of Minnesota Duluth

Duluth, MN 1039 University Drive, 55812 (USA)

E-mail:vnemykin@d.umn.edu

Supporting information for this article is available on the WWW under http://dx.doi.org/10.1002/chem.201404457. monolayers (SAMs). Porphyrin-based SAMs were intensively investigated recently by numerous research groups because of their remarkable electrochemical, electrocatalytic, and photophysical properties. ${ }^{[13]}$ Despite significant progress in preparation and characterization of porphyrin-containing SAMs, reports on surface immobilization of redox-active ferrocenyl-containing porphyrins and their analogues are rare. ${ }^{[14]}$ Moreover, recently we communicated the first example of ferrocenyl-containing porphyrin, which was linked to SAM by porphyrin-ferrocene-linker-Au covalent bond, ${ }^{[15]}$ whereas all other SAMs were prepared using porphyrin-linker-Au bonding or axial coordination to Au surface. ${ }^{[14]}$ Preliminary photocurrent generation experiments showed that the covalently bound metal-free TFCPs are able to catalytically reduce dioxygen under photostimulation. ${ }^{[14]}$ However, despite this uncommon and promising feature, the light-into-current conversion efficiency is much lower than that of other porphyrin-supported gold electrodes. ${ }^{[16]}$

Thus, herein we provide complete characterization of the unsymmetric tetraferrocenyl-containing porphyrins of general formula $\mathrm{Fc}_{3}(\mathrm{FcCOR})$ Por, where $\mathrm{R}=\mathrm{CH}_{3}$ (1), $\left(\mathrm{CH}_{2}\right)_{5} \mathrm{Br}$ (2), and $\left(\mathrm{CH}_{2}\right)_{5} \mathrm{SCOCH}_{3}(3)$, as well as an investigation on the kinetics of the electron transfer at the SAM/electrode interface in view of photocatalytic applications. 


\section{Results and Discussion}

\section{Synthesis and characterization of $\mathrm{Fc}_{3}(\mathrm{FcCOR})$ Por}

Classical Friedel-Crafts conditions for ferrocene provided inadequate yields for the functionalization of ferrocenecarboxyaldehyde (around $10 \%$ ). This is likely due to two simultaneous effects: 1) FcCHO is deactivated toward acylation because of the $\mathrm{CHO}$ electron-withdrawing group; 2) the aldehyde competes for the coordination of $\mathrm{AlCl}_{3}$, thus preventing the formation of the acylium ion. Indeed, as soon as aluminum chloride was added, the solution turned from orange into violet, which stems from the formation of a Lewis complex. To overcome these inconveniences, the acylium carbocation was prepared in a separate flask, while an $\mathrm{FcCHO}-\mathrm{AlCl}_{3}$ complex was formed in a second flask. Two equivalents of the acyl chloride were necessary to force the reaction to completion. With these modifications, the conversion was improved (up to $60-70 \%$ yields) using different acylating agents. The reaction is highly regioselective: among possible isomers, the only product observed was the $1,1^{\prime}$-disubstituted compound. Apparently, the introduction of a keto group at the 1 ' position deactivates the product, thus making a second substitution disfavored on both rings.

Mono-functionalized tetraferrocenylporphyrins $\mathbf{1}$ and $\mathbf{2}$ were prepared by a mixed condensation of $\mathrm{FcCHO}$ and functionalized $\mathrm{FcCHO}$ in 5:1 ratio using the standard statistical condensation method under the Lindsey cyclization conditions (Scheme 1). The stoichiometric ratio (3:1) was not adopted to avoid the formation of multisubstituted porphyrins, which would have complicated the isolation of the product. As a matter of fact, only traces of di-substituted isomers were isolated as by-products from the synthesis of 5-[1'-acetyl)ferrocenyl]-10,15,20-triferrocenylporphyrin. On the other hand, a ratio higher than 5:1 would have promoted the formation of an excess of $\mathrm{H}_{2} \mathrm{TFCP}$. Another issue responsible for the observed moderate yields is the scarce stability of the functionalized aldehydes in the reaction conditions employed.

No traces of these compounds were recovered after column chromatography, whereas a considerable amount of $\mathrm{FcCHO}$ was ubiquitous at the end of the reactions. Such evidence suggests that the decomposition of the 1'-substituted ferrocenecarboxyaldehydes is the main drawback in mono-substituted tetraferrocenylporphyrin synthesis.

After separation of $\mathbf{1}$ and $\mathbf{2}$ from side-reaction products, using conventional chromatography approach, complex $\mathbf{2}$ was transformed into thioacetyl derivative $\mathbf{3}$. This derivative undergoes in situ cleavage upon exposure to the gold surface to form $\mathrm{Fc}_{3}(\mathrm{FcCOR})$ Por $\left(\mathrm{R}=\left(\mathrm{CH}_{2}\right)_{5} \mathrm{SH}\right.$, 4) containing SAMs, thus avoiding handling unstable free-thiol porphyrin compounds.

The UV/Vis-NIR and MCD spectra of $\mathrm{FC}_{3}(\mathrm{FcCOR})$ Por derivatives $\mathbf{1}$ and $\mathbf{2}$ are presented in Figure 1. As expected from the similarity of electronic effects of $\mathrm{COCH}_{3}$ and $\mathrm{CO}\left(\mathrm{CH}_{2}\right)_{5} \mathrm{Br}$ groups, both spectra are very close to each other and consist of an intense Soret band located at $434 \mathrm{~nm}$, a shoulder at 490-495 nm range, and two prominent Q-bands observed at about 660 and $725 \mathrm{~nm}$. In both cases, the Soret band located at $437 \mathrm{~nm}$ is represented by Faraday pseudo $A$ term in their corresponding MCD spectra, while Q-bands are represented by negative (lower energy) and positive (higher energy) Faraday $B$ terms with energies close to the corresponding absorption bands. Furthermore, another Fadaray pseudo $A$ term was most likely observed at $499 \mathrm{~nm}$, which corresponds to a broad shoulder in the absorption spectrum of 1 and 2.

The consistency of MCD spectra of porphyrins 1 and 2 correlates well with the low symmetries of these compounds. Overall, UV/Vis and MCD spectra of 1 and $\mathbf{2}$ are very close to the reported earlier spectra of symmetric $\mathrm{H}_{2} \mathrm{TFCP}$ and unsymmetric $\mathrm{FC}_{n} \mathrm{Ph}_{(4-n)}$ Por derivatives. ${ }^{[17]}$

Similar to the described earlier metal-free and transition-metal tetraferrocenyl porphyrins, ${ }^{[6, m, p, q]}$ the redox properties of $\mathrm{Fc}_{3}(\mathrm{FcCOR})$ Por derivatives were initially evaluated using cyclic voltammetry (CV) and differential pulse voltammetry (DPV) approaches. To minimize soluteelectrolyte ion-pairing and thus

Scheme 1. Synthetic pathways for preparation of the $\mathrm{Fc}_{3}(\mathrm{FcCOR}) \mathrm{Por}$ derivatives and related SAMs. 


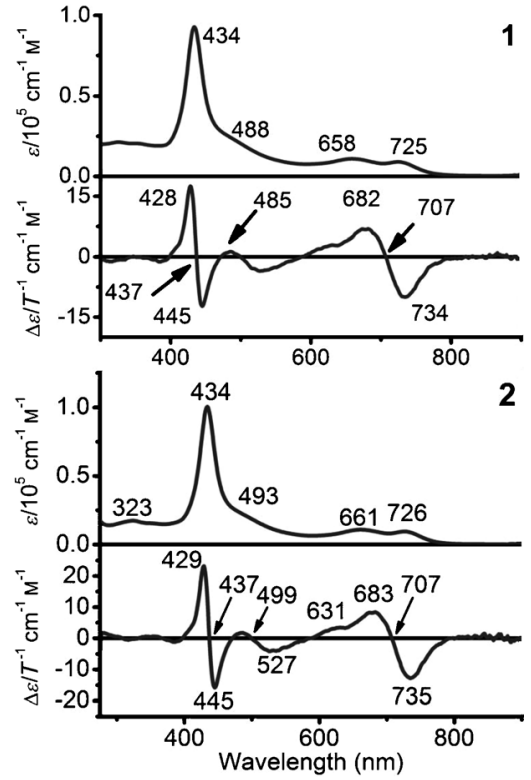

Figure 1. UV/Vis-NIR and MCD spectra of 1 (top) and 2 (bottom) in $\mathrm{CH}_{2} \mathrm{Cl}_{2}$.

improve the resolution between redox processes, all electrochemical and spectroelectrochemical experiments on $\mathrm{Fc}_{3}(\mathrm{FcCOR})$ Por porphyrins were conducted using $\mathrm{CH}_{2} \mathrm{Cl}_{2}$ as a solvent and, as suggested by Geiger and co-workers as well as other research groups, ${ }^{[18]}$ tetrabutylammonium tetrakis(perfluorophenyl)borate (TFAB) as the electrolyte.

$\mathrm{CV}$ and DPV results for $\mathrm{Fc}_{3}(\mathrm{FcCOR})$ Por compounds are shown in Figure 2, while redox potentials are listed in Table 1.

In agreement with redox data reported previously on $\mathrm{H}_{2}$ TFcP and MTFcP complexes, ${ }^{[6,, m, p, q]}$ redox processes in

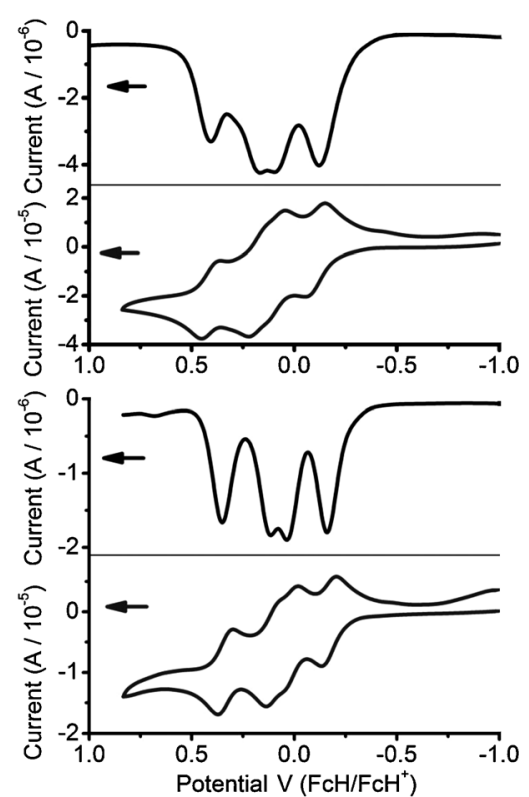

Figure 2. Electrochemical data ( $\mathrm{CV}, 50 \mathrm{mV} \mathrm{s}^{-1}$ and DPV) of compounds 1 (top) and 2 (bottom) in $\mathrm{CH}_{2} \mathrm{Cl}_{2} / 0.05 \mathrm{M}$ TFAB system in the oxidation region of the ferrocene substituents.

\begin{tabular}{|c|c|c|c|c|c|c|}
\hline Porphyrin & Ox4 & $0 \times 3$ & $0 \times 2$ & Ox1 & Red1 & Red2 \\
\hline $\mathrm{H}_{2} \mathrm{TFCP}^{[\mathrm{b}]}$ & 0.35 & 0.21 & 0.11 & -0.15 & -1.90 & -2.18 \\
\hline $\mathrm{Fc}_{3}(\mathrm{FcCOMe})$ Por & 0.46 & 0.21 & 0.15 & -0.07 & -1.84 & -2.10 \\
\hline $\mathrm{Fc}_{3}\left(\mathrm{FcCO}\left(\mathrm{CH}_{2}\right)_{5} \mathrm{Br}\right)$ Por & 0.44 & 0.20 & 0.12 & -0.07 & -1.82 & -2.03 \\
\hline
\end{tabular}

$\mathrm{FC}_{3}(\mathrm{FcCOR})$ Por could be associated with oxidation of ferrocene substituents and oxidation/reduction of the porphyrin core. All reductions are porphyrin-centered, reversible, and observed between -1.82 and $-2.1 \mathrm{~V}$, but because of the presence of an electron-withdrawing group, the porphyrin-centered oxidation process was not observed within the solvent window. It could be expected that an introduction of one ferrocene substituent with an electron-withdrawing group would result in: 1) a shift of redox potentials to a more positive region; and 2) a better separation between the ferrocene-centered redox waves because of its higher oxidation potential. Indeed, the oxidation potential of acetylferrocene was reported to be about $270 \mathrm{mV}$ more positive compared to that of the parent ferrocene. ${ }^{[19]}$ Moreover, an influence of the electron-withdrawing acyl ferrocene on the adjacent and the opposite unsubstituted ferrocene groups should also be slightly different, thus resulting in a better separation between redox waves. Not surprisingly, CV and DPV data on $\mathrm{Fc}_{3}(\mathrm{FcCOR})$ Por compounds support expected trends. In particular, the first and second, as well as the third and fourth oxidation waves, are very well separated, whereas separation between the second and the third oxidation waves is much smaller.

It is interesting to note that the total span for all four oxidation processes in $\mathrm{Fc}_{3}(\mathrm{FcCOR})$ Por compounds is still close to that observed in the parent $\mathrm{H}_{2} \mathrm{TFCPor}$, although the first oxidation potential in $\mathrm{Fc}_{3}(\mathrm{FcCOR})$ Por compounds is about $80 \mathrm{mV}$ more positive because of the electron coupling of the three unsubstituted ferrocene groups with electro-accepting acyl ferrocene fragment (Table 1).

Extracted from the electrochemical data, the comproportionation constants $\left(K_{c}\right)^{[20]}$ for all possible mixed-valence states in $\mathrm{Fc}_{3}(\mathrm{FcCOR})$ Por compounds are presented in Table 2. Based on CV and DPV data, it is expected that the $K_{c}$ for the following equilibria:

\begin{tabular}{|c|c|c|}
\hline $\mathrm{X}^{0}+\mathrm{X}^{2+} \rightleftarrows 2\left(\mathrm{X}^{+}\right)$ & $\mathrm{X}^{1+}+\mathrm{X}^{3+} \rightleftarrows 2\left(\mathrm{X}^{2+}\right)$ & $\mathrm{X}^{2+}+\mathrm{X}^{4+} \rightleftarrows 2\left(\mathrm{X}^{3+}\right)$ \\
\hline \multicolumn{3}{|c|}{$\mathrm{Fc}_{3}(\mathrm{FcCOMe}) \operatorname{Por}(\mathbf{1})$ : } \\
\hline 3832 & 14 & 13313 \\
\hline \multicolumn{3}{|c|}{$\mathrm{Fc}_{3}\left(\mathrm{FcCO}\left(\mathrm{CH}_{2}\right)_{5} \mathrm{Br}\right)$ Por (2): } \\
\hline 2056 & 19 & 11393 \\
\hline
\end{tabular}

[a] Comproportionation constants were calculated using $K_{c}=\exp [\Delta E \cdot F / R T]$ formula, where $F / R T=38.92 \mathrm{~V}^{-1}$ at $298 \mathrm{~K}$ (see Ref. [17a]). 
$\left[\mathrm{Fc}_{3}(\mathrm{FcCOR}) \mathrm{Por}\right]^{0}+\left[\mathrm{Fc}_{3}(\mathrm{FcCOR}) \mathrm{Por}\right]^{2+} \rightleftharpoons 2\left[\mathrm{Fc}_{3}(\mathrm{FcCOR}) \mathrm{Por}\right]^{+}$

$\left[\mathrm{Fc}_{3}(\mathrm{FcCOR}) \mathrm{Por}\right]^{2+}+\left[\mathrm{Fc}_{3}(\mathrm{FcCOR}) \mathrm{Por}\right]^{4+} \rightleftharpoons 2\left[\mathrm{Fc}_{3}(\mathrm{FcCOR}) \mathrm{Por}\right]^{3+}$

indicate higher stability of $\left[\mathrm{Fc}_{3}(\mathrm{FcCOR}) \mathrm{Por}\right]^{+}$and $\left[\mathrm{Fc}_{3}(\mathrm{FcCOR}) \mathrm{PorH}_{2}\right]^{3+}$ mixed-valence species in solution. Estimated values of $K_{\mathrm{c}}$ for the second and third oxidation process are significantly smaller (Table 2 ), reflecting possible difficulties with generation of spectroscopically pure $\left[\mathrm{Fc}_{3}(\mathrm{FcCOR}) \mathrm{Por}\right]^{2+}$ mixed-valence species. As usual, it should be noted that although estimated values of $K_{c}$ could be helpful in characterization of the mixed-valence species generated under spectroelectrochemical conditions, they should be treated with a great caution because of the well-known fact that the electrochemical redox potentials of potentially mixed-valence compounds are highly dependent on the solvent and the electrolyte. ${ }^{[19 a, b]}$

To obtain spectroscopic signatures of $\left[\mathrm{Fc}_{3}(\mathrm{FcCOR}) \mathrm{Por}\right]^{n+}$ species as well as to provide an accurate assignment of electrochemically observed redox processes, $\mathrm{Fc}_{3}(\mathrm{FcCOR})$ Por derivatives 1 and $\mathbf{2}$ were further investigated by spectroelectrochemical approaches.

In both cases, during oxidation under the first oxidation potential, the Soret band of 1 and 2 at about $435 \mathrm{~nm}$ was found to decrease in intensity and undergo a redshift of $28 \mathrm{~nm}$, whereas the Q-band was found to decrease in intensity without energy change. Furthermore, a very characteristic intervalence charge-transfer (IVCT) band appeared at about $905 \mathrm{~nm}$ (Figure 3; Supporting Information, Figure S1). The IVCT band energy and intensity are similar to those observed in the earlier described [TFcPor ${ }^{+}$and $\left[\right.$MTFcPor $^{+}$mixed-valence complexes. $^{[6 h, m, p, q]}$ Thus, the first transformation process could be confidently assigned to a $\quad \mathrm{Fc}_{3}(\mathrm{FcCOR}) \mathrm{Por} \rightarrow$

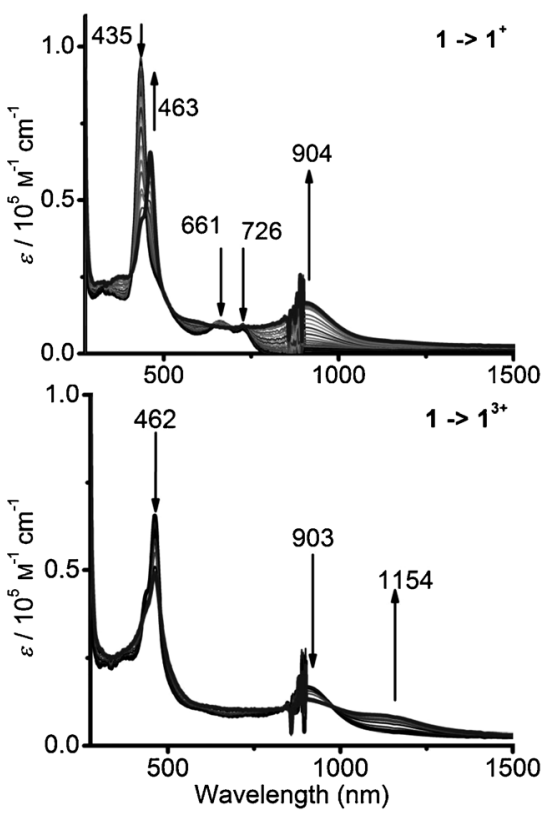

Figure 3. Spectroelectrochemical oxidation of the $\mathrm{Fc}_{3}(\mathrm{FcCOMe}) \mathrm{Por}(1)$ at first (top; $\mathbf{1} \rightarrow \mathbf{1}^{+}$) and second-third (bottom; $\mathbf{1}^{+} \rightarrow \mathbf{1}^{3+}$ ) oxidation potentials in DCM/0.15 M TFAB system
$\left[\mathrm{Fc}_{3}(\mathrm{FcCOR}) \mathrm{Por}\right]^{+}+\mathrm{e}^{-}$transformation. Further oxidation of the $\left[\mathrm{Fc}_{3}(\mathrm{FcCOR}) \mathrm{Por}\right]^{+}$species under spectroelectrochemical conditions resulted in the Soret band intensity decrease, a drop in intensity of the IVCT band, and the development of a new broad IVCT band at about 1150-1200 nm (Figure 3; Supporting Information, Figure S1). Taking into consideration the small difference between second and third oxidation waves as observed in electrochemical experiments and thus the relatively small values of comproportionation constants for $\left[\mathrm{Fc}_{3}(\mathrm{FcCOR}) \mathrm{Por}\right]^{+}+\left[\mathrm{Fc}_{3}(\mathrm{FcCOR}) \mathrm{Por}\right]^{3+} \rightleftarrows 2\left[\mathrm{Fc}_{3}(\mathrm{FcCOR}) \mathrm{Por}\right]^{2+}$ process, we did not attempt to obtain spectroscopic signature for $\left[\mathrm{Fc}_{3}(\mathrm{FcCOR}) \mathrm{Por}\right]^{2+}$ mixed-valence complex, but rather convert it into more stable $\left[\mathrm{Fc}_{3}(\mathrm{FcCOR}) \mathrm{Por}\right]^{3+}$ compound (Figure 3 ). The resulting spectra of the mixed-valence $\left[\mathrm{Fc}_{3}(\mathrm{FcCOR}) \mathrm{Por}\right]^{3+}$ species characterized by the presence of a very broad NIR IVCT band. Further oxidation of the previously generated mixed-valence species results in gradual disappearance of the entire spectrum, which can be attributed to the decrease in solubility of highly charged $\left[\mathrm{Fc}_{3}(\mathrm{FcCOR}) \mathrm{Por}\right]^{4+}$ species in low polarity solvent $\left(\mathrm{CH}_{2} \mathrm{Cl}_{2}\right)$. Such behavior was observed earlier with $\mathrm{H}_{2} \mathrm{TFCP}$ and MTFcP complexes. ${ }^{[6 h, m, p, q]}$

Spectroelectrochemical data were further supported by chemical oxidation of $\mathrm{Fc}_{3}(\mathrm{FcCOR})$ Por $\mathbf{1}$ and 2. In particular, chemical oxidation of $\mathrm{Fc}_{3}(\mathrm{FcCOR})$ Por derivatives by a controlled amount of 2,3-dichloro-5,6-dicyanobenzoquinone (DDQ), $\mathrm{I}_{2}, \mathrm{Br}_{2}$ or [NO]BF ${ }_{4}$ results in transformation of initial compounds 1 and 2 into mixed-valence $\left[\mathrm{Fc}_{3}(\mathrm{FcCOR}) \mathrm{Por}\right]^{+}$cations (Figure 4; Supporting Information, Figures S2 and S3). During these oxidations, Soret band shifts to the circa $460 \mathrm{~nm}$ region, Q-bands decrease in intensity, and a new, counterion-dependent IVCT band at about $900 \mathrm{~nm}$ appears in the UV/Vis-NIR spectra of $\left[\mathrm{Fc}_{3}(\mathrm{FcCOR}) \mathrm{Por}\right]^{+}$cations. Such transformation is in excellent agreement with the spectroelectrochemical data. Further oxidative titrations of the mixed-valence $\left[\mathrm{Fc}_{3}(\mathrm{FcCOR}) \mathrm{Por}\right]^{+}$com-
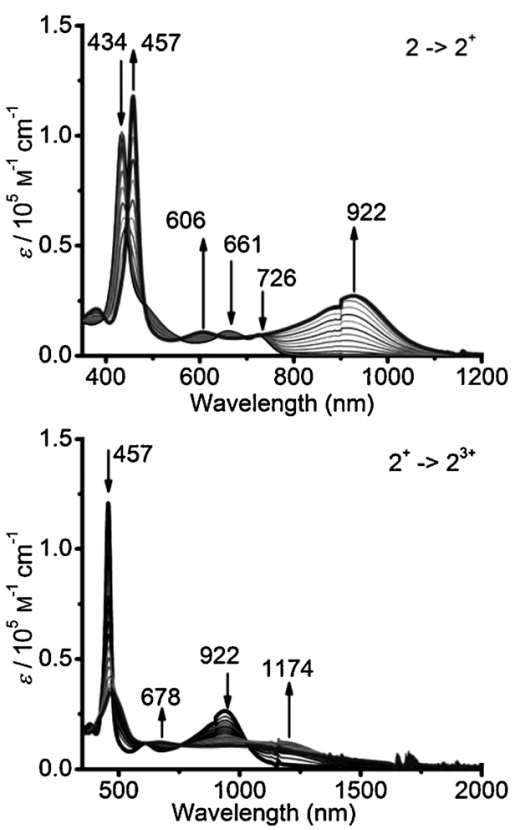

Figure 4. Stepwise chemical oxidation of derivative 2 by $[\mathrm{NO}] \mathrm{BF}_{4}$ in $\mathrm{CH}_{2} \mathrm{Cl}_{2}$. 
pounds result in the rise of a second broad IVCT band at about $1150 \mathrm{~nm}$ and decrease of the Soret band intensity, again in agreement with the spectroelectrochemical data (Figure 4; Supporting Information, Figures S2 and S3).

The Hush method ${ }^{[21]}$ is typically used for the initial analysis of experimental data in mixed-valence compounds. In the case of $\mathrm{Fc}_{3}(\mathrm{FcCOR})$ Por compounds, such analysis could be applied to the spectroelectrochemically or chemically generated mixed-valence $\left[\mathrm{Fc}_{3}(\mathrm{FcCOR}) \mathrm{Por}\right]^{+}$only because of the presence of a better-defined IVCT band in the NIR region of their UV/ Vis-NIR spectra. The two key parameters that are estimated using the Hush model are: the electronic coupling matrix element $\left(H_{\mathrm{ab}}\right)$ and the degree of delocalization $\left(\alpha^{2}\right)$. These parameters can be estimated using equations (1) and (2), with the $\mathrm{Fe}-\mathrm{Fe}$ distances extracted from the corresponding DFT predicted geometry of neutral $\mathrm{Fc}_{3}(\mathrm{FcCOMe})$ Por compound:

$H_{\mathrm{ab}}=2.05 \times 10^{-2}\left[\left(v_{\max } \varepsilon_{\max } \Delta v_{1 / 2}\right)^{1 / 2} / r_{\mathrm{ab}}\right]$

$\alpha^{2}=4.24 \times 10^{-4}\left[\left(\varepsilon_{\max } \Delta v_{1 / 2}\right) /\left(r_{\mathrm{ab}}^{2} v_{\max }\right)\right]$

The energy of the IVCT at band maximum in $\mathrm{cm}^{-1}$ is $v_{\max }$ $\Delta v_{1 / 2}$ is the width at the band maximum in $\mathrm{cm}^{-1}, \varepsilon_{\max }$ is the molar extinction coefficient of the IVCT, and $r_{\mathrm{ab}}$ is the distance between redox centers in $\AA$. Table 3 displays the parameters obtained from the IVCT band fits. These parameters should be considered with caution because of the relatively broad nature of the IVCT band in $\mathbf{1}^{+}$and $\mathbf{2}^{+}$, the uncertainty factor in band deconvolution analysis, and the possibility of protonation contribute into absorption in IVCT region. Thus, values listed in Table 3 are rough estimates that add support to the other spectroscopic data discussed above. In all cases, the $H_{\mathrm{ab}}$ and $\alpha$ values closely match the values obtained for the previously reported polyferrocenyl porphyrins, ${ }^{[6 h, m, p, q]}$ and are in the range of class II (Robin and Day classification) mixed-valence compounds. ${ }^{[22]}$

\section{Electronic structures of $\mathrm{Fc}_{3}(\mathrm{FcCOR})$ Por}

Density functional theory (DFT) calculations were performed to acquire insight into nature of the electronic structure, spectroscopy, and redox properties of $\mathrm{Fc}_{3}(\mathrm{FcCOR})$ Por derivatives. Be- cause of the great similarities in properties of $\mathbf{1}$ and $\mathbf{2}$, the electronic structure and excited state energies of only complex 1 were calculated. Similar to the reported earlier $\mathrm{H}_{2} \mathrm{TFCP}_{1}^{[17]}$ the compound $\mathrm{FC}_{3}(\mathrm{FcCOMe})$ Por is predicted to be highly nonplanar and adopt the most stable $\alpha, \beta, \alpha, \beta$-conformation. The molecular orbital energy diagram, molecular orbital compositions, and representative shapes of important molecular orbitals predicted using the BP86 exchange-correlation functional and $6-311 \mathrm{G}(\mathrm{d})$ basis set are shown in Figure 5 and 6.
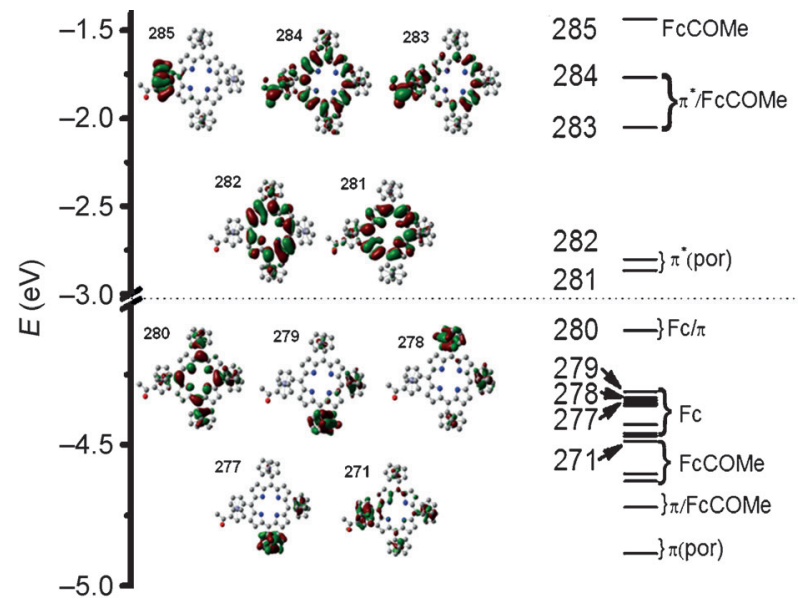

Figure 5. Molecular orbital diagram of $\mathrm{Fc}_{3}(\mathrm{FcCOMe}) \mathrm{Por}(1)$ calculated at the BP86 DFT level.

The electronic structure of $\mathrm{Fc}_{3}(\mathrm{FcCOMe})$ Por 1 has many similarities with the previously reported electronic structure of the parent $\mathrm{H}_{2}$ TFCP. $^{[17]}$ In particular: 1) the LUMO and LUMO +1 are predominantly porphyrin-centered $\pi^{*}$ orbitals that resemble Gouterman's ${ }^{[23]}$ classic $e_{g}$-symmetry MO pair; these orbitals are well-separated from the $\mathrm{LUMO}+2$, which has large contribution from acyl ferrocene group; 2 ) similar to all previously described MTFCP and $\mathrm{H}_{2}$ TFCP compounds, ${ }^{[6 h, m, p, q]}$ predominantly ferrocene-containing MOs have higher energies in comparison with the porphyrin-centered occupied $\pi$-orbitals; 3 ) the HOMO with predominant equatorial ferrocene group character has circa $25 \%$ porphyrin $\pi$-system character mostly located at meso-carbon and nitrogen atoms; 4) the $a_{2 u}$-type (with most electron density located at the meso-carbon and nitrogen atoms) porphyrin-centered $\pi$-orbital (HOMO) has a higher energy than the $a_{14}$-type (with most electron density located at the $\alpha$ - and $\beta$-carbon atoms) porphyrin-centered $\pi$-orbital (HOMO-12). Introduction of electron-withdrawing group in one of the ferrocene substituents results in large energy stabilization of the MOs associated with acyl ferrocene.

[a] SEC = spectroelectrochemistry. [b] The shortest Fe-Fe distance from DFT calculations on $\mathrm{Fc}_{3}(\mathrm{FcCOMe}) \mathrm{Por}$. All data are based on band deconvolution analysis of the IVCT region. 


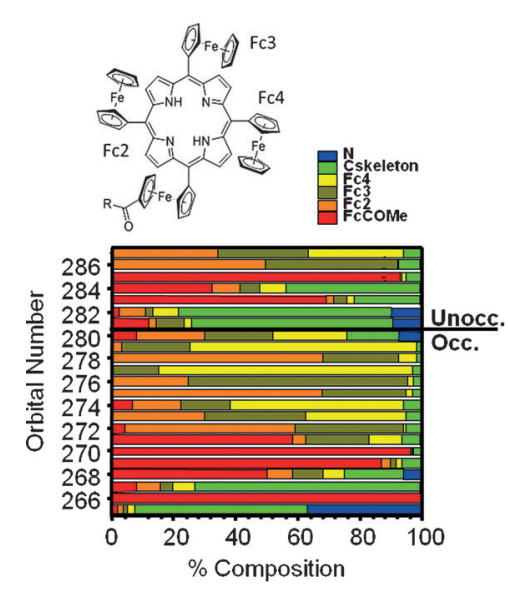

Figure 6. Molecular orbital compositions of $\mathrm{Fc}_{3}(\mathrm{FcCOMe})$ Por (1) calculated at the BP86 DFT level.

Although, acyl ferrocene group contributes about $8 \%$ into HOMO, predominantly acyl ferrocene-centered MOs are located between HOMO-9 and HOMO-11. On the other hand, the three more electron-rich unsubstituted ferrocene groups left behind dominate in $\mathrm{HOMO}$ to $\mathrm{HOMO}-8$ region. Interestingly, DFT predicts that the contribution from adjacent and opposite to acyl ferrocene group ferrocene substituents contribute nearly equally, which makes it difficult to clearly associate the first oxidation process with specific ferrocene substituents.

In contrast, a large stabilization of acyl ferrocene MOs clearly suggests that the fourth oxidation process in $\mathrm{Fc}_{3}(\mathrm{FcCOR})$ Por derivatives 1 and $\mathbf{2}$ should be centered on substituted ferrocene group. Unlike in the parent $\mathrm{H}_{2} \mathrm{TFCP}^{[17]}$ the $\mathrm{HOMO}$ is wellseparated (ca. $0.22 \mathrm{eV}$ ) from the HOMO-1. Similar to calculations on parent TFCPor, ${ }^{[17]}$ TDDFT predicts a large number of predominantly metal-to-ligand charge transfer (MLCT) bands in Q-band region of 1 heavily mixed into the porphyrin-centered $\pi-\pi^{*}$ transitions (Figure 7; Supporting Information, Figure S4 and Table S1).

In agreement with its electronic structure, the majority of unsubstituted ferrocene-to-porphyrin MLCT transitions were predicted in 700-900 $\mathrm{nm}$ region, whereas those that originated from acyl ferrocene were calculated in the circa $600 \mathrm{~nm}$ region.

\section{Electrolyte-tunable photocata- lytic efficiency of the mixed monolayer}

In a previous work, we have shown that TFcPs are able to form stable and well-packed selfassembled monolayers. ${ }^{[15]}$ In particular, a mixed SAM of 1-butanethiol and 5-[1'-(6-thioacetylhexanoyl)ferrocenyl]-10,15,20-triferrocenylporphyrin (Figure 8A) exhibited an interesting electrochemical behavior in which rificial electron acceptor.

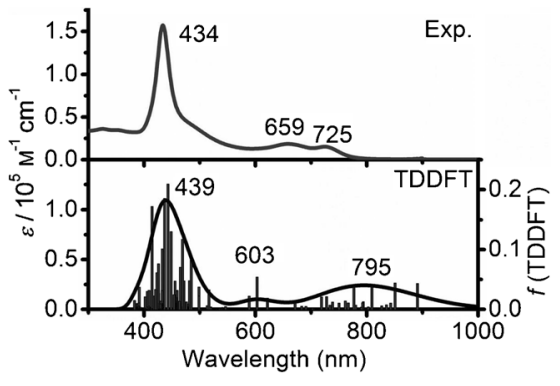

Figure 7. Experimental (top) and TDDFT predicted (bottom) UV/Vis spectra of 1 calculated at the BP86 DFT level.

a " $3+1$ " oxidation pattern in acetonitrile/TBAP system was detected. The same film is able to reduce the atmospheric dioxygen dissolved in water under photo-stimulation in the visible region of the spectrum, using $\mathrm{Na}_{2} \mathrm{SO}_{4}$ as the supporting electrolyte at $0.0 \mathrm{~V}$ applied potential. The reason for this lies in the strong donating character of the porphyrin in the excited state $\left(E^{*}{ }_{1 / 2}=-2.68 \mathrm{~V}\right.$ versus $\left.\mathrm{Ag} / \mathrm{AgCl}\right)$, which makes it able to pump electrons into the sacrificial acceptor.

The porphyrin is then reduced back to its neutral state by an electron transfer from the gold surface, which closes the photoelectrochemical circuit. However, in principle, three electrons are available for $\mathrm{O}_{2}$ reduction in such a polar environment. Moreover, as just described in the electrochemical section, mono-functionalized $\mathrm{H}_{2}$ TFCPs undergo four individual single-electron oxidations using a non-coordinating electrolyte in a non-polar solvent. Therefore, a water soluble precursor of TFAB, namely $\mathrm{Li}\left[\mathrm{B}\left(\mathrm{C}_{6} \mathrm{~F}_{5}\right)_{4}\right]$, is supposed to reduce the photo-catalytic activity of the porphyrin, because it is expected to separate the oxidation processes making the second and third process less favorable at applied $0.0 \mathrm{~V}$.

In spite of expectations, the resulting action spectrum (black line with light gray circles in Figure 9) is a noisy, ill-defined plot with a maximum in correspondence of the Soret band, where an $80 \%$ loss of intensity was detected with respect to the control experiment carried out using $\mathrm{Na}_{2} \mathrm{SO}_{4}$ (dark gray line with
A)

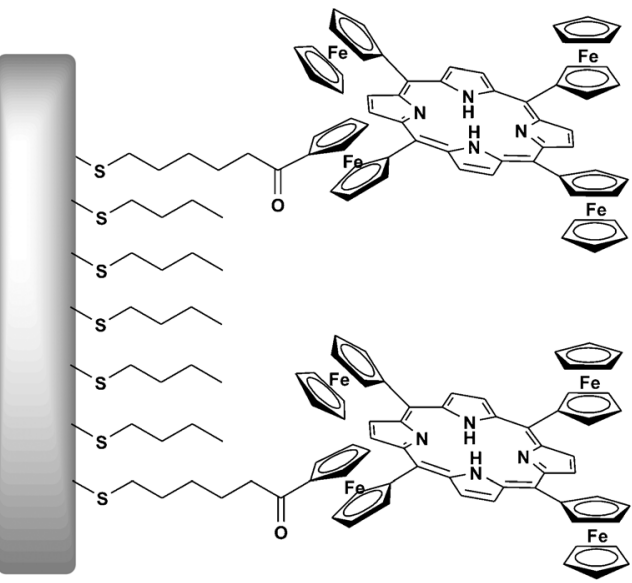

B)

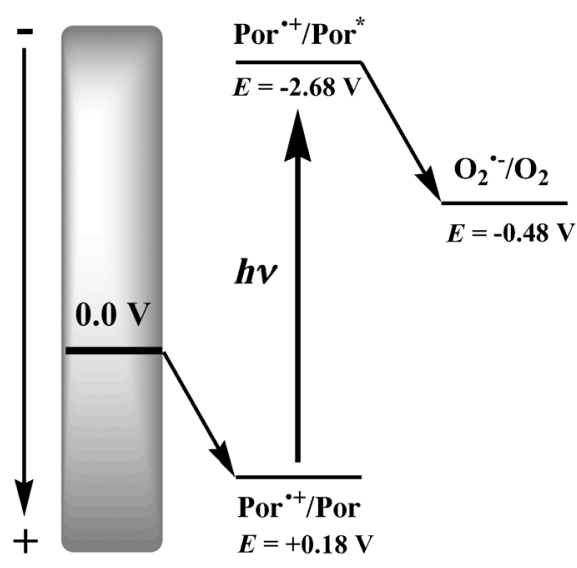

Figure 8. A) Representation of 4. B) The cathodic photocurrent generation mechanism using dioxygen as the sac- 


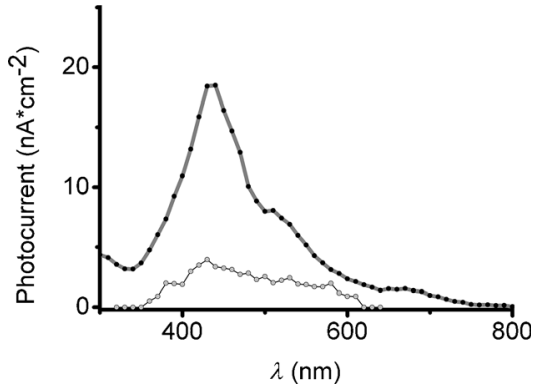

Figure 9. Overlapped action spectra of the mixed SAM obtained in an aqueous solution of $\mathrm{Na}_{2} \mathrm{SO}_{4} 0.1 \mathrm{M}$ (dark gray line with black circles) or in an aqueous solution of $\mathrm{Li}\left[\mathrm{B}\left(\mathrm{C}_{6} \mathrm{~F}_{5}\right)_{4}\right] 0.05 \mathrm{M}$ (black line with light gray circles). Both photocurrent generation experiments were carried out using $\mathrm{O}_{2}$ as the sacrificial electron acceptor.

black circles in Figure 9). Such a remarkable decrease can be explained with a poorer permeability of the bulky tetrakis(pentafluorophenyl)borate anion into the monolayer. This prevented the association with the redox center, thus increasing the activation energy for the oxidation of the porphyrin. ${ }^{[24]}$ Thus, the photocatalytic reduction of $\mathrm{O}_{2}$ was kinetically hindered by the encumbrance of the supporting electrolyte. On the other hand, this simple experiment demonstrated that the photocatalytic activity of the porphyrin can be easily tuned by the use of different electrolytes, opening the way for new switchable materials.

\section{Electrochemistry of the mixed SAM in aqueous media}

To confirm the kinetic control over the photocatalytic activity of the mixed SAM exerted by the electrolytes, CV and DPV experiments were performed using the same solutions employed in photocurrent generation (PG) experiments. In contrast to the above reported well-resolved four individual single electron oxidation processes, the electrochemical profiles of the modified electrodes resemble those reported in acetonitrile/ TBAP system, ${ }^{[15]}$ consisting of two redox waves (see the DPV in Figure 10) in which a " $3+1$ " mechanism of electron transfer can be recognized. Moreover, the first process was found to occur at a lower potential using tetrakis(pentafluorophenyl)borate anion, as suggested by the half-wave potentials in Table 4.

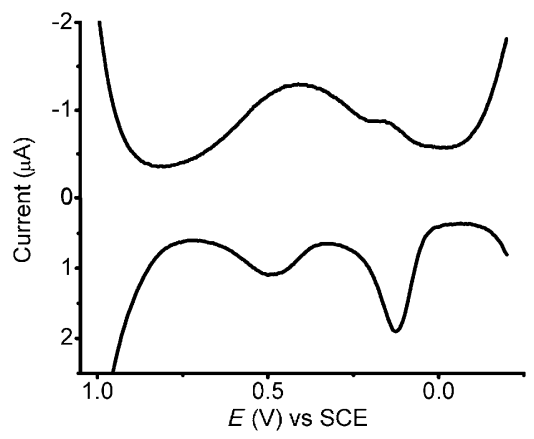

Figure 10. Representative DPV in the oxidative (bottom) and reductive (top) directions of the mixed SAM in an aqueous $0.05 \mathrm{M}$ solution of $\operatorname{Li}\left[B\left(C_{6} F_{5}\right)_{4}\right]$.
Table 4. Electron transfer rates and half-wave potentials for the first process of mixed SAM in aqueous solutions of $\mathrm{Na}_{2} \mathrm{SO}_{4}$ and $\mathrm{Li}\left[\mathrm{B}\left(\mathrm{C}_{6} \mathrm{~F}_{5}\right)_{4}\right]$.

\begin{tabular}{|lll|} 
& $k_{\mathrm{ET}}\left[\mathrm{s}^{-1}\right]$ & $E_{1 / 2}[\mathrm{mV}]$ \\
\hline $\mathrm{Na}_{2} \mathrm{SO}_{4}$ & $1.6 \cdot 10^{-3}$ & 180 \\
$\mathrm{Li}\left[\mathrm{B}\left(\mathrm{C}_{6} \mathrm{~F}_{5}\right)_{4}\right]$ & $2.5 \cdot 10^{-5}$ & 125 \\
\hline
\end{tabular}

This is reasonable, as an organic anion is expected to associate more strongly to a cationic porphyrin than sulfate anions. Although it makes the first process more favorable, $\mathrm{Li}\left[\mathrm{B}\left(\mathrm{C}_{6} \mathrm{~F}_{5}\right)_{4}\right]$ is not effective in the resolution of the first three-electron process and the reduction in the photocatalytic efficiency cannot be attributed to this effect.

Conversely, the kinetics of electron transfer play a significant role inasmuch as the association with the bulky counterion is too slow to occur during the short lifetime of the excited species. Indeed, CV at different scan rates underlined a quick broadening of the peaks and large values of the overpotential at low scan rates (see Figure 11). Instead, for an ideal electro-

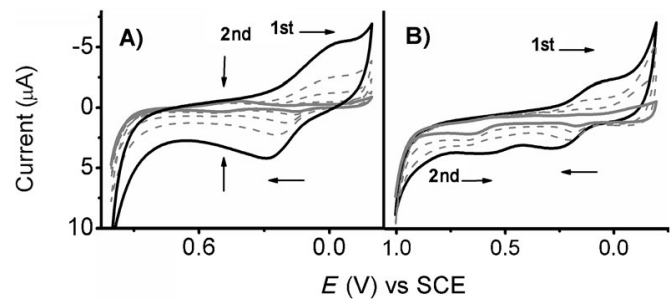

Figure 11. Overlapped $\mathrm{CV}$ at different scan rates $\left(5,10,25,50,100 \mathrm{mV} \mathrm{s}^{-1}\right)$ using the mixed SAM as working electrode in a $0.05 \mathrm{M}$ solution of $\mathrm{Li}\left[\mathrm{B}\left(\mathrm{C}_{6} \mathrm{~F}_{5}\right)_{4}\right]$ (A) and a $0.1 \mathrm{M}$ solution of $\mathrm{Na}_{2} \mathrm{SO}_{4}$ (B) in water.

chemical behavior of adsorbed species, the separation between the peaks $\left(\Delta E_{\mathrm{p}}=E_{\mathrm{pa}}-E_{\mathrm{pc}}\right)$ is required to be zero at low scan rates because diffusion does not take place. ${ }^{[25]}$ The large size of $\mathrm{B}\left(\mathrm{C}_{6} \mathrm{~F}_{5}\right)_{4}{ }^{-}$makes the approach and the removal to the redox sites hard, as the monolayer has to reorganize to accommodate and release the anions. As a consequence, peaks move in the opposite directions; that is, oxidation and reduction processes are more difficult as the scan rate increases. In particular, the most hindered site is the substituted ferrocenyl group, which lies embedded within the monolayer.

In fact, the second redox wave, attributed to this ferrocenyl group, drops to zero much faster than the first and is visible only below the scan rate of $25 \mathrm{mV} \mathrm{s}^{-1}$ (Figure $11 \mathrm{~A}$ ). A comparison between $\mathrm{CV}$ at variable scan rates reveals that peaks move slower with the scan rate when $\mathrm{Na}_{2} \mathrm{SO}_{4}$ is used as supporting electrolyte (Figure $11 \mathrm{~B}$ ). Furthermore, the second process is still visible at $v_{\mathrm{s}}>100 \mathrm{mV} \mathrm{s}^{-1}$, a clear indication that both the first and the second process are faster using $\mathrm{SO}_{4}{ }^{2-}$ as a consequence of its better permeability into the monolayer.

The rate constants for the electron transfer were calculated through the Laviron method ${ }^{[26]}$ and are presented in Table 4. The calculated values are much lower than those reported for other porphyrin-containing SAMs, ${ }^{[27]}$ which is probably because 
of the approximations introduced in the model (see the Experimental section), which are likely to underestimate the value of $k_{\mathrm{ET}}$. However, it should be emphasized that those values refer to the association of a single anion to the core of the macrocycle.

Instead, regarding to the first process of the TFCP-containing SAM, it requires the simultaneous arrival and accommodation of three anions in a well-packed monolayer (Figure 12). Thus, it

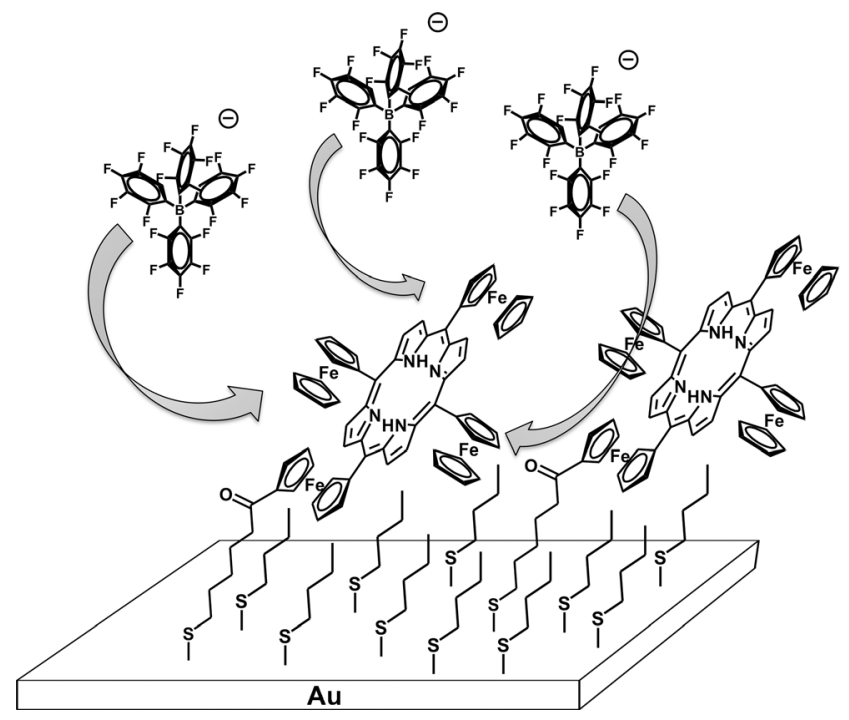

Figure 12. Representation of the simultaneous slow arrival of three tetrakis(pentafluorophenyl)borate anions required for the occurrence of the first oxidation process.

should not be surprising that the experimental values are lower than those expected for aryl porphyrins. However, $k_{\mathrm{ET}}$ were all obtained under the same assumptions that are not affected by different electrolytes. Therefore, albeit not completely reliable in absolute, these values can be efficiently compared. A significant decrease of two orders of magnitude in the rate of the electron transfer was found switching from $\mathrm{Na}_{2} \mathrm{SO}_{4}$ to $\mathrm{Li}\left[\mathrm{B}\left(\mathrm{C}_{6} \mathrm{~F}_{5}\right)_{4}\right]$ solutions (Table 4). This difference strongly supports the idea that quenching of the photocatalytic activity of the porphyrin is kinetically hampered by the exclusion of bulky anions from the monolayer, which prevents the association with the redox site. Under these circumstances, the electron delivery is slower than the excited state lifetime of the porphyrin and reduction of $\mathrm{O}_{2}$ does not take place.

\section{Conclusions}

Three new unsymmetric metal-free tetraferrocenyl-containing porphyrins of general formula $\mathrm{Fc}_{3}(\mathrm{FcCOR})$ Por have been prepared and characterized by variety of spectroscopic methods. The redox properties of all of the new compounds were also examined by electrochemical methods, while the nature of mixed-valence species of general formula $\left[\mathrm{Fc}_{3}(\mathrm{FcCOR}) \mathrm{Por}\right]^{\mathrm{n}+}$ was probed by spectroelectrochemical and chemical oxidation approaches. The electronic structure and nature of the excited states in target compounds were modeled by DFT and TDDFT calculations. It was suggested that the fourth oxidation process is associated with the substituted ferrocenyl group, while it remains ambiguous if the first oxidation process is centered at adjacent or opposite unsubstituted ferrocenyl moiety.

Stable and well-packed monolayers were formed on gold surface and the photoelectrochemical and electrochemical properties of the resulting modified electrodes were evaluated. Interestingly, a cathodic photocurrent was generated at zero applied bias potential using $\mathrm{O}_{2}$ as the sacrificial electron acceptor. Such a photocatalytic activity toward dioxygen can be tuned by the supporting electrolyte. Indeed, it was found to be quenched using a bulky anion like tetrakis(pentafluorophenyl)borate, as a consequence of its low ability to penetrate into the monolayer and associate to the oxidized porphyrin. Thus, the electron transfer rate at the gold-monolayer interface is slower than the porphyrin excited-state lifetime, and reduction of $\mathrm{O}_{2}$ does not take place. In particular, the results of this study offered elucidation for the electron transfer kinetic on TFCP SAM that should be taken into consideration in the development of application of these active molecules. The clarification of the fate of dioxygen and the eventual formation of partially reduced oxygen species is currently underway.

\section{Experimental Section}

\section{Materials}

All of the reactions were performed under a dry argon atmosphere with flame-dried glassware. All solvents and reagents were purchased from commercial sources and used without additional purification. Dry toluene was obtained by distillation over sodium, dry $\mathrm{CH}_{2} \mathrm{Cl}_{2}$ was obtained by distillation over calcium hydride prior to experiments, and dry THF was obtained by distillation over $\mathrm{Na}$ with benzophenone. Silica gel $(60 \AA, 63-100 \mu \mathrm{m})$ needed for column chromatography was purchased from Dynamic Adsorbents, while basic aluminum oxide (Activity I, $58 \AA$, 150 mesh) was purchased from Fischer Inc. The tetrabutylammonium tetrakis(pentafluorophenyl)borate (TBAF) was used in anhydrous $\mathrm{CH}_{2} \mathrm{Cl}_{2}$ for electrochemical studies, after preparation according to previously reported procedures. ${ }^{[15]}$

\section{Computational Aspects}

All of the computations were performed using Gaussian 09 software running under Windows or UNIX OS. ${ }^{[28]}$ Molecular orbital contributions were compiled from single point calculations using the QMForge program. ${ }^{[29]}$ In all single-point calculations and geometry optimizations, Becke's exchange functional and the Pedrew 86 correlation functional $(\mathrm{BP} 86)^{[30]}$ was used because as it was shown before, GGA-based exchange-correlation functionals provide a good electronic structure description for ferrocene-containing molecules, ${ }^{[31]}$ including ferrocenylporphyrins. ${ }^{[17]}$ Use of hybrid $B 3 L_{Y P}{ }^{[32]}$ or PBE1PBE ${ }^{[33]}$ exchange-correlation functionals lead to heavy infusion of porphyrin-centered $\pi$-electron density into the HOMO region, which was not supported by the experimental data. Wachters' full-electron basis set was used for iron, ${ }^{[34]}$ while for all other atoms $6-311 \mathrm{G}(\mathrm{d})$ basis $\mathrm{set}^{[35]}$ was employed. The first 120 states were predicted in TDDFT calculations. 


\section{Instrumentation}

A Bruker AMX 300 NMR instrument was used to obtain spectra at $300 \mathrm{MHz}$ frequency for protons and a Bruker AMX 400 NMR at $100 \mathrm{MHz}$ for carbons. Each spectrum was referenced to TMS as an internal standard and chemical shifts were recorded in parts per million. All UV/Vis data were obtained on a JASCO-720 spectrophotometer at room temperature. An OLISDCM 17 CD spectropolarimeter with 1.4 TDeSa magnet was used to obtain all MCD data. Electrochemical measurements were conducted using a $\mathrm{CHI}-620 \mathrm{C}$ electrochemical analyzer utilizing the three-electrode scheme. Either carbon or platinum working, auxiliary, and reference electrodes were used in $0.05 \mathrm{M}$ solution of TBAF in $\mathrm{CH}_{2} \mathrm{Cl}_{2}$ with redox potentials corrected using an internal standard (decamethylferrocene) in all cases. Spectroelectrochemical data were collected using a custom-made $0.1 \mathrm{~mm}$ cell, a working electrode made of platinum mesh, and a $0.15 \mathrm{M}$ solution of TBAF in DCM. A PalmSense potentiostat was employed in CV and DPV experiments of SAMs. Photocurrent generation experimetns were carried out using a PG-310 potentiostat (HEKA Elektronik, Lambrecht, Germany). The samples were excited by a xenon lamp located in a Fluoromax-2 fluorimeter (Jobin Yvo, France).

\section{Preparation of SAMs}

The gold foils were electrochemically polished according to a wellestablished procedure. ${ }^{[36]}$ SAMs were prepared as previously described ${ }^{[15]}$ that is by soaking the gold electrode in a $0.2 \mathrm{~mm}$ solution of the porphyrin in dichloromethane containing 5 equiv of 1 butanethiol for $20 \mathrm{~h}$. The gold foils were then thoroughly rinsed with $\mathrm{CH}_{2} \mathrm{Cl}_{2}$ and dried with $\mathrm{N}_{2}$. Film formation was monitored by cyclic voltammetry using $\mathrm{K}_{3}\left[\mathrm{Fe}(\mathrm{CN})_{6}\right]$ as redox probe. SAMs resulted well-packed and porphyrin density was estimated to be $\Gamma=(8 \pm$ 2) $\times 10^{-11} \mathrm{~mol} \mathrm{~cm}^{2}$, in excellent agreement with our previously reported work. ${ }^{[15]}$

\section{Photocurrent generation (PG) experiments}

Photocurrent experiments were carried out either in a $0.1 \mathrm{M}$ solution of $\mathrm{Na}_{2} \mathrm{SO}_{4}$ or in a $0.05 \mathrm{M}$ solution of $\mathrm{Li}\left[\mathrm{B}\left(\mathrm{C}_{6} \mathrm{~F}_{5}\right)_{4}\right]$ in double-distilled water using the atmospheric dioxygen dissolved in water as the electron acceptor. A functionalized gold foil was used as the working electrode, whereas an $\mathrm{Ag} / \mathrm{AgCl}$ and a Pt wire were employed as reference and counter electrodes, respectively. Measurements were undertaken alternating phases of 45 seconds of light with 30 seconds of darkness at zero applied bias potential. The whole visible spectrum was investigated and data were collected every $10 \mathrm{~nm}$. A step graph of the photocurrent intensity as a function of time was obtained in which every step is taken at different wavelengths. The plot of the height of each step as a function of the wavelength affords the action spectrum of the desired compound. The height of a step is calculated as the difference between the average of the intensities on the step and the average of the intensities of the adjacent phases of darkness. Each action spectrum was normalized by the immersed area of the gold electrode.

\section{Electrochemistry of SAMs}

CV and DPV experiments were carried out using a three-electrode setup with SCE as the reference electrode and a platinum wire as the counter electrode. The same modified gold surfaces employed in PG experiments were used as working electrodes. A $0.1 \mathrm{M}$ solution of $\mathrm{Na}_{2} \mathrm{SO}_{4}$ or a $0.05 \mathrm{M}$ solution of $\mathrm{Li}\left[\mathrm{B}\left(\mathrm{C}_{6} \mathrm{~F}_{5}\right)_{4}\right]$ in double-distilled water were employed as the solvent-electrolyte couples. $\Gamma$ was calculated by the integral of the peak of the first oxidation process as previously described. ${ }^{[15]} k_{\mathrm{ET}}$ values were determined performing subsequent CV experiments at variable scan rates through the Laviron method (see the next section).

Because of the complete insolubility of $\mathrm{FCH}^{+} \mathrm{PF}_{6}{ }^{-}$in aqueous $\mathrm{Li}\left[\mathrm{B}\left(\mathrm{C}_{6} \mathrm{~F}_{5}\right)_{4}\right]$ solution, potentials were not referred to the redox couple $\mathrm{FcH}^{+} / \mathrm{FcH}$. However, in the case of $\mathrm{Na}_{2} \mathrm{SO}_{4} / \mathrm{H}_{2} \mathrm{O}$, potentials could be eventually adjusted by $-0.180 \mathrm{~V}$.

\section{Data analysis}

The Laviron method ${ }^{[26]}$ was employed to estimate the electrontransfer rate constant of the first redox process, whereas the second process was too slow for $k_{\mathrm{ET}}$ determination with this approach. Such a method was applied under the assumption that the first process involves the simultaneous removal of three electrons, while redox centers were treated as non-interacting. Also, as $\mathrm{CV}$ peaks were too broad at scan rates higher than $100 \mathrm{mV} \mathrm{s}^{-1}$, a linear region in the graph of the overpotential $\left(\eta=E_{\mathrm{p}}-E_{1 / 2}\right)$ versus $\log \left(v_{\mathrm{s}}\right)$ could not be reached, so that the transfer coefficient $\alpha$ could not be experimentally determined. Therefore, $k_{\mathrm{ET}}$ was estimated assuming the ideal situation in which $\alpha=0.5$, that is, symmetric energy barriers for the redox reactions were considered. ${ }^{[25]}$ Under these simplifications, the electron transfer rate constant was determined as the intercept of the straight line obtained by the plot of $\Delta E_{\mathrm{p}} v s \log \left(v_{\mathrm{s}}\right)$ according to the equation: $:^{[37]}$

$$
\Delta E_{\mathrm{p}}=\left[\frac{2.3 R T}{\alpha(1-\alpha) n F}\right]\left\{\alpha \log (1-\alpha)+\left(1-\alpha \log \alpha+\log \frac{n F}{R T}-\log \kappa_{\mathrm{ET}}+\log v_{\mathrm{s}}\right\}\right.
$$

where $n$ is number of electrons transferred during the process $(n=$ 3 for the first process of the mixed SAM), $\Delta E_{\mathrm{p}}=E_{\mathrm{a}}-E_{\mathrm{c}}, T$ is the temperature in $\mathrm{K}, R$ is the ideal gas constant in $\mathrm{JK}^{-1} \mathrm{~mol}^{-1}, F$ is the Faraday constant in $\mathrm{Cmol}^{-1}$, and $v_{\mathrm{s}}$ is the scan rate in $\mathrm{Vs}^{-1}$.

\section{Syntheses}

Synthesis of 1'-(6-bromohexanoyl)ferrocencarboxaldehyde, 5-[1'-(6bromohexanoyl)ferrocenyl]-10,15,20-triferrocenylporphyrin and its thioacetyl derivative were previously described. ${ }^{[15]}$

1'-Acetylferrocencarboxaldehyde: Aluminum chloride $(0.37 \mathrm{~g}$, 1.2 equiv) was slowly added in portions to a solution of $\mathrm{FCCHO}$ $(0.5 \mathrm{~g}, 2.34 \mathrm{mmol})$ in anhydrous $\mathrm{CH}_{2} \mathrm{Cl}_{2}(15 \mathrm{~mL})$ under a nitrogen stream. In another flask, freshly distilled acetyl chloride $(4.68 \mathrm{mmol}$, $334 \mu \mathrm{L}$; 2 equiv) was dissolved in anhydrous $\mathrm{CH}_{2} \mathrm{Cl}_{2}$ (15 mL) under a nitrogen stream. 2.4 equivalents of $\mathrm{AlCl}_{3}(0.75 \mathrm{~g})$ were slowly added to this solution. The solution containing the acetyl chloride was then added dropwise to that containing $\mathrm{FcCHO}$ in $20 \mathrm{~min}$ at $0^{\circ} \mathrm{C}$. After this period, the reaction was carried out at room temperature and under a nitrogen atmosphere for $3 \mathrm{~h}$. The reaction was then quenched by the addition of ice (ca. $100 \mathrm{~g}$ ) and $\mathrm{NH}_{4} \mathrm{Cl}$ $(5 \mathrm{~g})$, and extracted with $\mathrm{CH}_{2} \mathrm{Cl}_{2}$. The crude product was chromatographed on silica gel using a hexane/AcOEt mixture $(3: 2 \mathrm{v} / \mathrm{v})$ as the eluent. The solvent was removed under reduced pressure and the product was dissolved in diethyl ether and filtered. The solvent was evaporated again and the red solid was dissolved in the minimum volume of $\mathrm{CH}_{2} \mathrm{Cl}_{2}$ and precipitate with hexane to obtain $455 \mathrm{mg}$ of the pure product (76\% yield). ${ }^{1} \mathrm{H}$ NMR $\left(\mathrm{CDCl}_{3}\right): \delta=9.96$ $(\mathrm{s}, 1 \mathrm{H}, \mathrm{CHO}), 4.87(\mathrm{t}, 2 \mathrm{H}, \mathrm{CH} \alpha), 4.83\left(\mathrm{t}, 2 \mathrm{H}, \mathrm{CH} \alpha^{\prime}\right), 4.63(\mathrm{t}, 2 \mathrm{H}, \mathrm{CH}$ $\left.\beta^{\prime}\right), 4.59(\mathrm{t}, 2 \mathrm{H}, \mathrm{CH} \beta), 2.39 \mathrm{ppm}\left(\mathrm{s}, 3 \mathrm{H}, \mathrm{CH}_{3}\right) ;{ }^{13} \mathrm{C} \mathrm{NMR}\left(\mathrm{CDCl}_{3}\right): \delta=$ 200.78 (CO acetyl), 192.63 (CO aldehyde), 80.21-79.79 $\left(C_{1}-C_{1}{ }^{\prime}\right), 74.11$ 
(Cp $\beta), 72.96\left(\mathrm{Cp} \beta^{\prime}\right), 70.62,70.46\left(\mathrm{Cp} \alpha-\mathrm{Cp} \alpha^{\prime}\right), 27.28$ ppm $\left(\mathrm{CH}_{3}\right)$. MS (E.I.): $m / z 256\left(M^{+}\right)$.

5-[(1'-acetyl)ferrocenyl]-10,15,20-triferrocenylporphyrin (1): 1'acetylferrocencarboxaldehyde $(200 \mathrm{mg}, 0.78 \mathrm{mmol})$ and $\mathrm{FcCHO}$ (835 mg, $3.89 \mathrm{mmol}$ ) were mixed in dry $\mathrm{CH}_{2} \mathrm{Cl}_{2}(125 \mathrm{~mL})$ together with pyrrole $(325 \mu \mathrm{L}, 4.67 \mathrm{mmol}) . \mathrm{BF}_{3} \cdot \mathrm{Et}_{2} \mathrm{O}(10 \%, 58 \mu \mathrm{L})$ was slowly added to this solution. All additions were performed under a nitrogen stream. The reaction mixture was stirred for $20 \mathrm{~h}$ at room temperature, in the dark and in a nitrogen atmosphere. After this period, chloranil $(480 \mathrm{mg}$ ) was added and the mixture was stirred at room temperature for $30 \mathrm{~min}$. The solution was concentrated and filtered over neutral $\mathrm{Al}_{2} \mathrm{O}_{3}$ deactivated with $5 \%$ of water using chloroform as eluent. The crude product was then chromatographed over $\mathrm{Al}_{2} \mathrm{O}_{3}$ deactivated with $10 \%$ of water, using the mixture hexane/ $\mathrm{CHCl}_{3} 3: 2 \mathrm{v} / \mathrm{v}$ as eluent. From the first fraction $\mathrm{H}_{2} \mathrm{TFCP}$ was collected in $15 \%$ yield. The second compound eluted was the unreacted $\mathrm{FcCHO}$, while the third was the target mono-substituted porphyrin. The solution containing the target porphyrin was evaporated under reduced pressure and the green solid was dissolved in the minimum volume of toluene and precipitated with hexane. The precipitate was then filtered to obtain a dark green powder $\left(63 \mathrm{mg}, 7 \%\right.$ yield). ${ }^{1} \mathrm{H}$ NMR $\left(\mathrm{CDCl}_{3}\right): \delta=9.66(\mathrm{~m}, 6 \mathrm{H}, \mathrm{H} \beta-$ pyrrolic), 9.67 (d, $2 \mathrm{H}, \mathrm{H} \beta$-pyrrolic), 9.54 (d, $2 \mathrm{H}, \mathrm{H} \beta$-pyrrolic), 5.39 $\left(\mathrm{t}, 2 \mathrm{H}, \mathrm{Cp} \alpha^{\prime}\right), 5.36(\mathrm{t}, 8 \mathrm{H}, \mathrm{Cp} \alpha), 4.80(\mathrm{t}, 8 \mathrm{H}, \mathrm{Cp} \beta), 4.78(\mathrm{t}, 2 \mathrm{H}, \mathrm{Cp}$ $\beta^{\prime} 4.02\left(\mathrm{~s}, 5 \mathrm{H}, \mathrm{Cp}\right.$ trans) $4.00\left(\mathrm{~s}, 10 \mathrm{H}, \mathrm{Cp}\right.$ cis), $3.27\left(\mathrm{t}, 2 \mathrm{H}, \mathrm{CH}_{2} \mathrm{Br}\right.$ ), $2.54\left(\mathrm{t}, 2 \mathrm{H}, \mathrm{CH}_{2} \mathrm{CO}\right),-0.5 \mathrm{ppm}(\mathrm{s}, 2 \mathrm{H}$, internal $\mathrm{NH}) .{ }^{13} \mathrm{C} \mathrm{NMR}$ $\left(\mathrm{CDCl}_{3}\right): \delta=202.03$ (CO), 145.45 (broad, $\alpha$-pyrr), 131.12, 130.90, 130.83130 .28 ( $\beta$-pyrr), 118.05, 117.64, 114.39 (meso C), 90.94, 89.07, 79.37 (ipso $C$ ), $77.67\left(C_{1}{ }^{\prime}\right.$ on substituted $\mathrm{Fc}$ ), 76.92, 76.87, 76.17, 71.27, 71.09, 69.10 (Cp $\left.\alpha, \alpha^{\prime}, \beta, \beta^{\prime}\right), 70.40$ (Cp trans), 70.38 (Cp cis), $27.58 \mathrm{ppm}\left(\mathrm{CH}_{3}\right)$; HRMS (ESI): $\mathrm{m} / \mathrm{z} 1089.1311\left(\mathrm{MH}^{+}\right)$; calcd for $\mathrm{C}_{62} \mathrm{H}_{49} \mathrm{Fe}_{4} \mathrm{~N}_{4} \mathrm{O}: 1089.1306$.

\section{Acknowledgements}

Generous support from the NSF CHE, Minnesota Supercomputing Institute, and U of M Grant-in-Aid to V.N. is greatly appreciated. P.G. thanks PRIN 2010-2011 project 2010M738P for funding support, Michela Gasparini and Fabio Possanza for the synthesis of $\mathrm{Fc}_{3}(\mathrm{FcCOMe})$ Por and Prof. Olga Bortolini for HRMS.

Keywords: electrochemistry - ferrocene - photocatalysis porphyrins $\cdot$ self-assembled monolayers

[1] a) Y. Wu, W. Zhu, Chem. Soc. Rev. 2013, 42, 2039; b) S. K. Balasingam, M. Lee, M. G. Kang, Y. Jun, Chem. Commun. 2013, 49, 1471; c) L.-L. Li, E. W.G. Diau, Chem. Soc. Rev. 2013, 42, 291; d) M. Grätzel, Acc. Chem. Res. 2009, 42, 1788; e) M. García-Iglesias, J.-J. Cid, J.-H. Yum, A. Forneli, P. Vazquez, M. K. Nazeeruddin, E. Palomares, M. Grätzel, T. Torres, Energy Environ. Sci. 2011, 4, 189; f) A. Hagfeldt, M. Grätzel, A. F. Nogueria L. F. O. Furtado, A. L. B. Formiga, M. Nakamura, K. Araki, H. E. Toma, S. Panigrahi, T. Pal, Chemtracts 2004, 17, 175; g) X. Chen, C. Li, M. Graetzel, R. Kostecki, S. S. Mao, Chem. Soc. Rev. 2012, 41, 7909; h) M. K. Nazeeruddin, E. Baranoff, M. Graetzel, Solar Energy 2011, 85, 1172; i) M. M. Lee, J. Teuscher, T. Miyasaka, T. N. Murakami, H. J. Snaith, Science 2012, 338, 643 ; j) R. H. Crabtree, Organometallics 2011, 30, 17; k) A. C. Jacko, R. H. McKenzie, B. J. Powell, J. Mater. Chem. 2010, 20, 10301; I) W.-Y. Wong, C.-L. Ho, Acc. Chem. Res. 2010, 43, 1246.

[2] a) W. Kaim, B. Sarkar, Coord. Chem. Rev. 2007, 251, 584; b) B. Fabre, Acc. Chem. Res. 2010, 43, 1509; c) Ferrocenes: Ligands, Materials and Biomolecules (Ed.: P. Stepnicka), John Wiley and Sons, Ltd., Chichester, England, 2008, pp. 655
[3] a) V. N. Nemykin, N. Kobayashi, Chem. Commun. 2001, 165; b) E. A. Lukyanets, V. N. Nemykin, J. Porphyrins Phthalocyanines 2010, 14, 1; c) L. Sun, S. Wang, H. Tian, Chem. Lett. 2007, 36, 250.

[4] a) Z. Jin, K. Nolan, C. R. McArthur, A. B. P. Lever, C. C. Leznoff, J. Organomet. Chem. 1994, 468, 205; b) K.-W. Poon, Y. Yan, X. Y. Li, D. K. P. Ng, Organometallics 1999, 18, 3528; c) V. N. Nemykin, E. A. Lukyanets, ARKIVOC 2010, 2010, 136; d) M. An, S. Kim, J.-D. Hong, Bull. Korean Chem. Soc 2010, 31, 3272; e) A. González-Cabello, C. G. Claessens, G. Martin-Fuch, I. Ledoux-Rack, P. Vázquez, J. Zyss, F. Agulló-López, T. Torres, Synth. Met. 2003, 137, 1487; f) I. Ömeroğlu, T. Arslan, Z. Biyiklioğlu, G. Tosun, J. Organomet. Chem. 2014, 749, 261; g) V. N. Nemykin, A. A. Purchel, A. D. Spaeth, M. V. Barybin, Inorg. Chem. 2013, 52, 11004; h) J. T. F. Lau, X.-J. Jiang, D. K. P. Ng, P.-C. Lo, Chem. Commun. 2013, 49, 4274; i) U. Salan, A. Altindal, M. Bulut, O. Bekaroglu, J. Porphyrins Phthalocyanines 2006, 10, 1263.

[5] a) G. Pomarico, A. Vecchi, F. Mandoj, O. Bortolini, D. O. Cicero, P. Galloni, R. Paolesse, Chem. Commun. 2014, 50, 4076; b) D. T. Gryko, J. Piechowska, J. S. Jaworski, M. Galezowski, M. Tasior, M. Cembor, H. Butenschoen, New J. Chem. 2007, 31, 1613.

[6] a) M. Su, Q. Li, Y. Wang, S. Chen, H. Zhao, Z. Bian, Chin. J. Org. Chem 2013, 33, 815; b) N. M. Loim, N. V. Abramova, V. I. Sokolov, Mendeleev Commun. 1996, 6, 46; c) A. K. Burrell, W. M. Campbell, G. B. Jameson, D. L. Officer, P. D. W. Boyd, Z. Zhao, P. A. Cocks, K. C. Gordon, Chem. Commun. 1999, 637; d) S. J. Narayanan, S. Venkatraman, S. R. Dey, B. Sridevi, V. R. G. Anand, T. K. Chandrashekar, Synlett 2000, 1834; e) S. W. Rhee, Y. H. Na, Y. Do, J. Kim, Inorg. Chim. Acta 2000, 309, 49; f) O. Shoji, S. Okada, A. Satake, Y. Kobuke, J. Am. Chem. Soc. 2005, 127, 2201; g) O. Shoji, H. Tanaka, T. Kawai, Y. Kobuke, J. Am. Chem. Soc. 2005, 127, 8598; h) S. J. Dammer, P. V. Solntsev, J. R. Sabin, V. N. Nemykin, Inorg. Chem. 2013, 52, 9496; i) M. Kubo, Y. Mori, M. Otani, M. Murakami, Y. Ishibashi, M. Yasuda, K. Hosomizu, H. Miyasaka, H. Imahori, S. Nakashima, J. Phys. Chem. A 2007, 111, 5136; j) V. N. Nemykin, C. D. Barrett, R. G. Hadt, R. I. Subbotin, A. Y. Maximov, E. V. Polshin, A. Y. Koposov, Dalton Trans. 2007 3378; k) J. Rochford, A. D. Rooney, M. T. Pryce, Inorg. Chem. 2007, 46, 7247; I) V. N. Nemykin, P. Galloni, B. Floris, C. D. Barrett, R. G. Hadt, R. I. Subbotin, A. G. Marrani, R. Zanoni, N. M. Loim, Dalton Trans. 2008, 4233; m) V. N. Nemykin, G. T. Rohde, C. D. Barrett, R. G. Hadt, C. Bizzarri, P. GalIoni, B. Floris, I. Nowik, R. H. Herber, A. G. Marrani, R. Zanoni, N. M. Loim, J. Am. Chem. Soc. 2009, 131, 14969; n) P. Galloni, B. Floris, L. De Cola, E. Cecchetto, R. M. Williams, J. Phys. Chem. C 2007, 111, 1517; o) V. N. Nemykin, G. T. Rohde, C. D. Barrett, R. G. Hadt, J. R. Sabin, G. Reina, P. Galloni, B. Floris, Inorg. Chem. 2010, 49, 7497; p) G. T. Rohde, J. R. Sabin, C. D. Barrett, V. N. Nemykin, New J. Chem. 2011, 35, 1440; q) P. V. Solntsev, B. D. Neisen, J. R. Sabin, N. N. Gerasimchuk, V. N. Nemykin, J. Porphyrins Phthalocyanines 2011, 15, 612.

[7] a) R. Sharma, P. Gautam, S. M. Mobin, R. Misra, Dalton Trans. 2013, 42, 5539; b) Y. Pareek, M. Ravikanth, J. Organomet. Chem. 2013, 724, 67; c) S. Samanta, K. Mittra, K. Sengupta, S. Chatterjee, A. Dey, Inorg. Chem 2013, 52, 1443; d) C. H. Devillers, A. Milet, J.-C. Moutet, J. Pecaut, G. Royal, E. Saint-Aman, C. Bucher, Dalton Trans. 2013, 42, 1196; e) E. Y. Osipova, A. N. Rodionov, A. A. Simenel, Y. A. Belousov, O. M. Nikitin, V. V. Kachala, J. Porphyrins Phthalocyanines 2012, 16, 1225; f) V. N. Nemykin, P. Chen, P. V. Solntsev, A. A. Purchel, K. M. Kadish, J. Porphyrins Phthalocyanines 2012, 16, 793; g) M. A. Bakar, N. N. Sergeeva, T. Juillard, M. O. Senge, Organometallics 2011, 30, 3225; h) D. M. Lyons, J. Mohanraj, G. Accorsi, N. Armaroli, P. D. W. Boyd, New J. Chem. 2011, 35, 632; i) N. K. Subbaiyan, C. A. Wijesinghe, F. D'Souza, J. Am. Chem. Soc. 2009, 131, 14646.

[8] a) A. K. Burrell, W. Campbell, D. L. Officer, Tetrahedron Lett. 1997, 38 1249; b) A. K. Burrell, W. M. Campbell, D. L. Officer, S. M. Scott, K. C. Gordon, M. R. McDonald, J. Chem. Soc. Dalton Trans. 1999, 3349; c) L. Jiao, B. H. Courtney, F. R. Fronczek, K. M. Smith, Tetrahedron Lett. 2006, 47, 501; d) H. J. H.; Wang, L. Jaquinod, M. M. Olmstead, M. G. H. Vicente, K. M. Kadish, Z. Ou, K. M. Smith, Inorg. Chem. 2007, 46, 2898; Wang, L. Jaquinod, M. M. Olmstead, M. G. H. Vicente, K. M. Kadish, Z. Ou, K. M. Smith, Inorg. Chem. 2007, 46, 2898; e) D. T. Gryko, F. Zhao, A. A. Yasseri, K. M. Roth, D. F. Bocian, W. G. Kuhr, J. S. Lindsey, J. Org. Chem. 2000, 65, 7356; f) E. S. Schmidt, T. S. Calderwood, T. C. Bruice, Inorg. Chem. 1986, 25, 3718; g) K.-L. Cheng, H.-W. Li, D. K. P. Ng, J. Organomet. Chem. 2004, 689,1593 ; h) R. Giasson, E. J. Lee, X. Zbao, M. S. Wrighton, J. Phys. Chem. 1993, 97, 2596; i) T. Muraoka, K. Kinbara, T. Aida, Nature 2006, 440, 512. 
[9] a) G. B. Maiya, J. M. Barbe, K. M. Kadish, Inorg. Chem. 1989, 28, 2524 b) P. V. Solntsev, J. R. Sabin, S. J. Dammer, N. N. Gerasimchuk, V. N. Nemy kin, Chem. Commun. 2010, 46, 6581; c) K. M. Kadish, Q. Y. Xu, J. M Barbe, Inorg. Chem. 1987, 26, 2565; d) Q. Y. Xu, J. M. Barbe, K. M. Kadish, Inorg. Chem. 1988, 27, 2373.

[10] a) A. Vecchi, P. Galloni, B. Floris, V. N. Nemykin, J. Porphyrins Phthalocyanines 2013，17，165; b) B. M. J. M. Suijkerbuijk, R. J. M. K. Gebbink Angew. Chem. 2008, 120, 7506; Angew. Chem. Int. Ed. 2008, 47, 7396.

[11] a) C. J. Ziegler, K. Chanawanno, A. Hasheminsasab, Y. V. Zatsikha, E. Maligaspe, V. N. Nemykin, Inorg. Chem. 2014, 53, 4751; b) V. Bandi, M. E. ElKhouly, K. Ohkubo, V. N. Nesterov, M. E. Zandler, S. Fukuzumi, F. D'Souza J. Phys. Chem. C 2014, 118, 2321; c) R. Misra, B. Dhokale, T. Jadhav, S. M. Mobin, Dalton Trans. 2013, 42, 13658; d) O. Galangau, I. Fabre-Francke S. Munteanu, C. Dumas-Verdes, G. Clavier, R. Meallet-Renault, R. B. Pansu, F. Hartl, F. Miomandre, Electrochim. Acta 2013, 87, 809; e) J.-Y Liu, M. E. El-Khouly, S. Fukuzumi, D. K. P. Ng, ChemPhysChem 2012, 13, 2030; f) R. Ziessel, T. Bura, J.-H. Olivier, Synlett 2010, 2304.

[12] a) H. Liu, J. Xu, Y. Li, Y. Li, Acc. Chem. Res. 2010, 43, 1496; b) Y. Li, T. Liu, H. Liu, M.-Z. Tian, Y. Li, Acc. Chem. Res. 2014, 47, 1186.

[13] a) R. Martin, R. Cao, F.-P. Montforts, P.-L. Noeske, New J. Chem. 2013, 37, 1610 ; b) K. Sugawa, S. Hirono, T. Akiyama, S. Yamada, Photochem. Photobiol. Sci. 2012, 11, 318; c) Y.-J. Cho, T. K. Ahn, H. Song, K. S. Kim, C. Y. Lee W. S. Seo, K. Lee, S. K. Kim, D. Kim, J. T. Park, J. Am. Chem. Soc. 2005, 127,2380 ; d) L. Liu, H. Xie, H. E. Bostic, L. Jin, M. D. Best, X. P. Zhang, W. Zhan, ChemPhysChem 2013, 14, 2777; e) M. Isosomppi, N. V. Tkachenko, A. Efimov, K. Kaunisto, K. Hosomizu, H. Imahori, H. Lemmetyinen, J. Mater. Chem. 2005, 15, 4546; f) W. Wang, Y. Hu, C. Wang, X. Lu, Electrochim. Acta 2012, 65, 244; g) S. Samanta, P. K. Das, S. Chatterjee, K. Sengupta, B. Mondal, A. Dey, Inorg. Chem. 2013, 52, 12963; h) C. Huang, Y. Li, Y. Song, Y. Li, H. Liu, D. Zhu, Adv. Mater. 2010, 22, 3532.

[14] a) H. Imahori, M. Kimura, K. Hosomizu, T. Sato, T. K. Ahn, S. K. Kim, D. Kim, Y. Nishimura, I. Yamazaki, Y. Araki, O. Ito, S. Fukuzumi, Chem. Eur. J. 2004, 10, 5111; b) K. Sengupta, S. Chatterjee, S. Samanta, S. Bandyopadhyay, A. Dey, Inorg. Chem. 2013, 52, 2000; c) P. Zhu, P. Ma, Y. Wang, Q. Wang, X. Zhao, X. Zhang, Eur. J. Inorg. Chem. 2011, 4241.

[15] A. Vecchi, E. Gatto, B. Floris, V. Conte, M. Venanzi, V. N. Nemykin, P. GalIoni, Chem. Commun. 2012, 48, 5145.

[16] P. Galloni, A. Vecchi, A. Coletti, E. Gatto, B. Floris, V. Conte in Handbook of Porphyrin Science, Vol. 33 (Eds.: K. M. Kadish, K. M. Smith, R. Guilard), World Scientific, Singapore, 2014, pp. 225.

[17] a) L. Zhang, D. Qi, Y. Zhang, Y. Bian, J. Jiang, J. Mol. Graphics Modell. 2011, 29, 717; b) V. N. Nemykin, R. G. Hadt, J Phys Chem. A 2010, 114, 12062.

[18] a) F. Barrière, W. E. Geiger, J. Am. Chem. Soc. 2006, 128, 3980; b) W. E. Geiger, N. G. Connelly, Adv. Organomet. Chem. 1985, 24, 87; c) E. A. Poppitz, A. Hildebrandt, M. Korb, H. Lang, J. Organomet. Chem. 2014, 752, 133; d) P. V. Solntsev, S. V. Dudkin, J. R. Sabin, V. N. Nemykin, Organometallics 2011, 30, 3037; e) A. Hildebrandt, S. W. Lehrich, D. Schaarschmidt R. Jaeschke, K. Schreiter, S. Spange, H. Lang, Eur. J. Inorg. Chem. 2012 1114; f) A. Hildebrandt, D. Schaarschmidt, R. Claus, H. Lang, Inorg. Chem. 2011, 50, 10623; g) A. Hildebrandt, D. Schaarschmidt, H. Lang, Organometallics 2011, 30, 556; h) W. R. Goetsch, P. V. Solntsev, C. Van Stappen A. A. Purchel, S. V. Dudkin, V. N. Nemykin, Organometallics 2014, 33, 145

[19] N. G. Connelly, W. E. Geiger, Chem. Rev. 1996, 96, 877.

[20] a) D. M. D'Alessandro, F. R. Keene, Chem. Soc. Rev. 2006, 35, 424; b) D. M. D'Alessandro, F. R. Keene, Dalton Trans. 2004, 3950; c) A. Donoli, A. Bisello, R. Cardena, C. Prinzivalli, M. Crisma, S. Santi, Organometallics 2014, 33, 1135; d) J. Alvarez, T. Ren, A. E. Kaifer, Organometallics 2001, 20, 3543; e) I. M. Piglosiewicz, R. Beckhaus, G. Wittstock, W. Saak, D. Haase, Inorg. Chem. 2007, 46, 7610; f) J. Jiao, G. J. Long, L. Rebbouh, F. Grandjean, A. M. Beatty, T. P. Fehlner, J. Am. Chem. Soc. 2005 127, 17819; g) Y. Zhao, D. Guo, Y. Liu, C. He, C. Duan, Chem. Commun. 2008, 5725; h) B. Schneider, S. Demeshko, S. Neudeck, S. Dechert, F.
Meyer, Inorg. Chem. 2013, 52, 13230; i) K. Tahara, T. Akita, S. Katao, J.-I. Kikuchi, Dalton Trans. 2014, 43, 1368.

[21] a) N. S. Hush, Prog. Inorg. Chem. 1967, 8, 391; b) C. Creutz, Prog. Inorg. Chem. 1983, 30, 1; c) N. S. Hush, Coord. Chem. Rev. 1985, 64, 135.

[22] M. B. Robin, P. Day, Adv. Inorg. Chem. Radiochem. 1968, 10, 247.

[23] M. Gouterman, J. Mol. Spectrosc. 1961, 6, 138.

[24] J. Jiao, M. Taniguchi, J. S. Lindsay, D. F. Bocian, Langmuir 2010, 26, 15718.

[25] A. L. Eckermann, D. J. Feld, J. A. Shaw, T. J. Meade, Coord. Chem. Rev. 2010, 254, 1769.

[26] E. Laviron, Electroanal. Chem. 1979, 101, 19.

[27] a) N. K. Devaraj, R. A. Decreau, W. Ebina, J. P. Collman, C. E. D. Chidsey, J. Phys. Chem. B 2006, 110, 15955; b) K. M. Roth, D. T. Gryko, C. Clausen, J. Li, J. S. Lindsay, W. G. Kuhr, D. F. Bocian, J. Phys. Chem. B 2002, 106, 8639.

[28] Gaussian 09, Revision A.1, M. J. Frisch, G. W. Trucks, H. B. Schlegel, G. E. Scuseria, M. A. Robb, J. R. Cheeseman, G. Scalmani, V. Barone, B. Mennucci, G. A. Petersson, H. Nakatsuji, M. Caricato, X. Li, H. P. Hratchian, A. F. Izmaylov, J. Bloino, G. Zheng, J. L. Sonnenberg, M. Hada, M. Ehara, K. Toyota, R. Fukuda, J. Hasegawa, M. Ishida, T. Nakajima, Y. Honda, O. Kitao, H. Nakai, T. Vreven, J. A. Montgomery Jr., J. E. Peralta, F. Ogliaro, M. Bearpark, J. J. Heyd, E. Brothers, K. N. Kudin, V. N. Staroverov, R. Kobayashi, J. Normand, K. Raghavachari, A. Rendell, J. C. Burant, S. S. Iyengar, J. Tomasi, M. Cossi, N. Rega, J. M. Millam, M. Klene, J. E. Knox, J. B. Cross, V. Bakken, C. Adamo, J. Jaramillo, R. Gomperts, R. E. Stratmann, O. Yazyev, A. J. Austin, R. Cammi, C. Pomelli, J. W. Ochterski, R. L. Martin, K. Morokuma, V. G. Zakrzewski, G. A. Voth, P. Salvador, J. J. Dannenberg, S. Dapprich, A. D. Daniels, O. Farkas, J. B. Foresman, J. V. Ortiz, J. Cioslowski, D. J. Fox, Gaussian, Inc., Wallingford CT, 2009.

[29] QMForge program: http://qmforge.sourceforge.net/.

[30] a) A. D. Becke, Phys. Rev. A 1988, 38, 3098; b) J. P. Perdew, Phys. Rev. B 1986, 33, 8822.

[31] a) R. H. Herber, I. Nowik, J. O. Grosland, R. G. Hadt, V. N. Nemykin, J. Organomet. Chem. 2008, 693, 1850; b) V. N. Nemykin, E. A. Makarova, J. O. Grosland, R. G. Hadt, A. Y. Koposov, Inorg. Chem. 2007, 46, 9591; c) V. N. Nemykin, A. Y. Maximov, A. Y. Koposov, Organometallics 2007, 26, 3138; d) V. N. Nemykin, J. G. Olsen, E. Perera, P. Basu, Inorg. Chem. 2006, 45, 3557; e) V. N. Nemykin, R. G. Hadt, Inorg. Chem. 2006, 45, 8297; f) Y. L. Li, L. Han, Y. Mei, J. Z. H. Zhang, Chem. Phys. Lett. 2009, 482, 217; g) F. Fabrizi de Biani, G. Manca, L. Marchetti, P. Leoni, S. Bruzzone, C. Guidotti, A. Atrei, A. Albinati, S. Rizzato, Inorg. Chem. 2009, 48, 10126; h) F. Li, R. Sa, K. Wu, Mol. Phys. 2008, 106, 2537; i) S. Santi, L. Orian, A. Donoli, C. Durante, A. Bisello, P. Ganis, A. Ceccon, L. Crociani, F. Benetollo, Organometallics 2007, 26, 5867; j) W.-W. Zhang, Y.-G. Yu, Z.-D. Lu, W.-L. Mao, Y.-Z Li, Q.-J. Meng, Organometallics 2007, 26, 865; k) M. Parac, S. Grimme, J. Phys. Chem. A 2002, 106, 6844; I) P. V. Solntsev, K. L. Spurgin, J. R. Sabin, A. A. Heikal, V. N. Nemykin, Inorg. Chem. 2012, 51, 6537; m) S. W. Lehrich, A. Hildebrandt, T. Rueffer, M. Korb, P. J. Low, H. Lang, Organometallics 2014, 33, 4836.

[32] a) A. D. Becke, J. Chem. Phys. 1993, 98, 5648; b) C. Lee, W. Yang, R. G. Parr, Phys. Rev. B 1988, 37, 785.

[33] C. Adamo, V. Barone, J. Chem. Phys. 1999, 110, 6158.

[34] A. J. H. Wachters, J. Chem. Phys. 1970, 52, 1033.

[35] a) A. D. McLean, G. S. Chandler, J. Chem. Phys. 1980, 72, 5639; b) P. J. Hay, W. R. Wadt, J. Chem. Phys. 1985, 82, 299.

[36] Y. Xiao, R. Y. Lai, K. W. Plaxco, Nat. Protoc. 2007, 2, 2875.

[37] C. Orain, P. Le Poul, Y. Le Mest, N. Le Poul, J. Electroanal. Chem. 2013, $710,48$.

Received: July 17, 2014

Published online on October 30, 2014 